Org Lett. 2007 October 25; 9(22): 4467-4469. doi:10.1021/ol701799c.

\title{
Synthetic Modification of Manzamine A via Grubbs Metathesis. Novel Structures with Enhanced Antibacterial and Antiprotozoal Properties
}

\author{
Jeffrey D. Winkler ${ }^{\star}, \dagger$, Allyn T. Londregan ${ }^{\dagger}$, and Mark T. Hamann ${ }^{*}, \neq$ \\ tDepartment of Chemistry, University of Pennsylvania, Philadelphia, Pennsylvania 19104 \\ ‡Department of Pharmacognosy, University of Mississippi, Oxford, Mississippi 38677
}

\begin{abstract}
A strategy for the structural modification of biologically important alkene-containing natural products via ring-opening olefin metathesis is described. Exposure of manzamine A 1 to the second-generation Grubbs catalyst in the presence of ethylene leads to the formation of 2 and 4. The antibacterial activity of the novel manzamine analogue $2\left(\mathrm{IC}_{50}=0.10 \mathrm{nM}\right)$ against Mycobacterium intracellulare is ca. 2-fold more potent than that of ciprofloxacin $\left(\mathrm{IC}_{50}=0.18\right.$ $\mathrm{nM}$ ), a drug that is frequently used against antibiotic-resistant infections.
\end{abstract}

\section{Abstract}
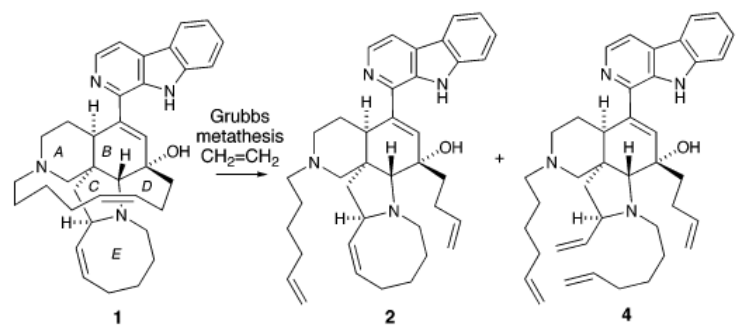

The synthesis of novel structures with important biological properties remains an important challenge. Natural products have often served as lead structures for the development of new chemotherapeutic agents because they enjoy both biological activity and bioavailability. ${ }^{1} \mathrm{We}$ outline herein a strategy for the transformation of naturally occurring compounds to novel structures using olefin metathesis as the key step. ${ }^{2}$

While the literature is now replete with examples of the use of olefin metathesis for the formation of cyclic structures, ${ }^{3}$ the metathesis reaction was first developed as a ring-opening reaction (ROMP) by Grubbs and co-workers. ${ }^{4}$ We have applied this idea to the ring-opening metathesis reaction of cycloalkene-containing natural products, notably manzamine A, $\mathbf{1}$.

winkler@sas.upenn.edu.

Supporting Information Available:

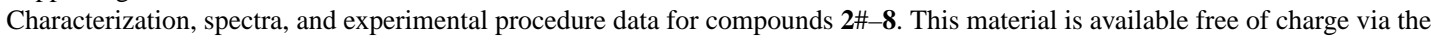
Internet at http://pubs.acs.org. 
Manzamine A and related structures are highly potent, orally bioavailable antimalarial agents that are more effective than most currently available therapeutics, i.e., chloroquine and artemisinin. ${ }^{5}$ In addition, some members of the manzamine family have also exhibited activity against the AIDS-opportunistic infectious diseases including tuberculosis and toxoplasmosis. We have recently described the de novo synthesis and biological activity of partial structures of manzamine A, $1{ }^{6}$ We report herein that the structural modification of manzamine A using olefin metathesis leads to the highly efficient formation of novel structures with important biological properties.

In an effort to determine the importance of the pentacyclic ring system in the observed antimalarial and antiinfective properties of $\mathbf{1}$, we sought to prepare analogues of $\mathbf{1}$ lacking either or both of the D and E rings, as shown in 2-4. We reasoned that exposure of $\mathbf{1}$ to ethylene and the Grubbs catalyst could lead to the formation of these three new analogues, in which the $\mathrm{D}$ ring, the $\mathrm{E}$ ring, and both the $\mathrm{D}$ and $\mathrm{E}$ rings, respectively, were cleaved by ringopening metathesis with ethylene to generate tetracyclic [i.e., $\mathbf{2}$ (ABCE) and $\mathbf{3}$ (ABCD)] and tricyclic [i.e., $4(\mathrm{ABC})$ ] analogues of manzamine $\mathrm{A}$. The presence of multiple basic amine functionalities in $\mathbf{1}$ would appear to preclude successful reaction with the Grubbs catalyst. ${ }^{7}$ However, exposure of the hydrochloride salt of 1 to $15 \mathrm{~mol} \%$ of the second-generation Grubbs catalyst under one atmosphere of ethylene at $25^{\circ} \mathrm{C}$ leads to the formation of a $4: 1$ mixture of manzamine-derived diene 2 and tetraene 4 in 73\% combined yield (Scheme 1). This remarkable reaction leads to the selective formation of one of the two possible tetracyclic analogues as well as the tricyclic analogue of manzamine A in just two steps from 1.

The selective formation of $\mathbf{2}$ in the metathesis ring opening of $\mathbf{1}$ and the failure to observe $\mathbf{3}$ under our reaction conditions is consistent with the partitioning of $\mathbf{1}$ between $\mathbf{2}$ (major) and $\mathbf{3}$ (minor). The formation of $\mathbf{3}$ must then be followed by a rapid ring-opening of the macrocyclic tether to generate $\mathbf{4}$. In contrast, the azocine alkene of $\mathbf{2}$ is inert under these reaction conditions, a result that can be attributed to the more stable conformation of the azocine ring in $\mathbf{2}$ relative to that of $\mathbf{1}$. In accord with this analysis, exposure of $\mathbf{3}$ (vide infra) to the metathesis reaction conditions leads to the rapid formation of $\mathbf{4}$.

The preparation of tetracyclic analogue $\mathbf{3}$ was achieved by the reaction sequence outlined in Scheme 2. Regioselective dihydroxylation of the $\Delta^{15,16}$ macrocyclic alkene of $\mathbf{1}$ led to the stereoselective formation of the 15,16-dihydroxy-manzamine $\mathbf{5}$. Diacetylation of $\mathbf{5}$ generated $\mathbf{6}$, the substrate for the Grubbs metathesis opening of the azocine ring. Exposure of $\mathbf{6}$ to the Grubbs catalyst led to the formation of the ring-opened product $\mathbf{7}$ in $90 \%$ yield, based on recovered starting material. Hydrolysis of the diacetate, followed by reaction of the derived diol with thiocarbonyldiimidazole, provided 8. Our initial attempts at regeneration of the $\Delta^{15,16}$ macrocyclic alkene by reaction of $\mathbf{8}$ with triethylphosphite led to the loss of the C-12 tertiary carbinol. Treatment of the derived C-12 silyl ether with triethylphosphite under the same reaction conditions led to the regeneration of the $\Delta^{15,16}$ alkene, with the retention of the C-12 silyl ether. Deprotection of the intermediate silyl ether with fluoride afforded $\mathbf{3}$, the net result of metathetic ring opening of the azocine ring of manzamine A, $\mathbf{1}$. 
The results of the biological testing of these new analogues are presented in Table 1. None of the new analogues are more potent than manzamine A against Plasmodium falciparum, although both of the tetracyclic analogues $\mathbf{2}(\mathrm{ABCE})$ and $\mathbf{3}$ (ABCD) are within an order of magnitude of $\mathbf{1}$ in their antimalarial activity.

The tetracyclic analogue $\mathbf{2}$ (ABCE) is more potent than $\mathbf{1}$ in both antimicrobial and leischmanicidal activity and is comparable or superior to currently available standard therapies, i.e., ciprofloxacin and pentamidine, respectively. As noted in the table, the activity of $2(0.10 \mathrm{nM})$ against the AIDS-opportunistic infection Mycobacterium intracellulare is greater than that of $\mathbf{1}(0.36 \mathrm{nM})$ and ca. 2-fold more potent than ciprofloxacin $(0.18 \mathrm{nM})$, a clinically important antibacterial therapeutic. The antileishmania activity of $\mathbf{2}$ is equally impressive $(2.1 \mathrm{nM})$. It is superior to that of $\mathbf{1}(6.2 \mathrm{nM})$ and to that of pentamidine $(47 \mathrm{nM})$, a clinically important antiprotozoal agent. It is particularly noteworthy that compound $\mathbf{2}$ $\left(\mathrm{TC}_{50}>8.1 \mathrm{nM}\right)$ is almost 4 times less toxic than manzamine $\mathrm{A}\left(\mathrm{TC}_{50}=2.2 \mathrm{nM}\right)$, an important indication of the potential importance of these new compounds as therapeutic agents.

These results underscore the significance of the covalent modification of manzamine A that leads, in two chemical steps, to a new analogue $\mathbf{2}$, which is superior to $\mathbf{1}$ both against a clinically important AIDS-opportunistic infection and against lechmaniasis. Further studies on the structural modification of this important lead compound are currently underway in our laboratory, and our results will be reported in due course.

\section{Supplementary Material}

Refer to Web version on PubMed Central for supplementary material.

\section{Acknowledgment}

We warmly thank Professor Amir Hoveyda (Boston College) for helpful discussions. The generous financial support of the NIH, GlaxoSmithKline, Merck, Amgen, Wyeth, and Boehringer-Ingelheim is gratefully acknowledged.

\section{References}

(1). (a) Rollinger JM, Langer T, Stuppner H. Curr. Med. Chem. 2006; 13:1491-1507. For recent reviews, see: [PubMed: 16787200] (b) Sehgal R, Nandave M, Ojha SK. Pharm. Rev. 2006; 4:40 44.(c) Salem M, Werbovetz K. MCurr. Med. Chem. 2006; 13:2571-2598.(d) Ferreira C, Justo G, Souza A, Queiroz K, Zambuzzi W, Aoyama H, Peppelenbosch M. Biochimie. 2006; 88:18591873. [PubMed: 17010496] (e) Thibodeaux C, Liu H. Pure Appl. Chem. 2007; 79:785-799.(f) Wipf P, Graham T, Xiao J. Pure Appl. Chem. 2007; 79:753-761.(g) Altmann K, Pfeiffer B, Arseniyadis S, Pratt B, Nicolaou KC. ChemMedChem. 2007; 2:396-423. [PubMed: 17340668] (h) Lessmann T, Leuenberger M, Menninger S, Lopez-Canet M, Mueller O, Huemmer S, Bormann J, Korn K, Fava E, Zerial M, Mayer T, Waldmann H. Chem. Biol. 2007; 14:443-451. [PubMed: 17462579]

(2). Ratnayake A, Hemscheidt T. Org. Lett. 2002; 4:4667-4669. For the application of this strategy to the elucidation of the structure of a naturally occurring compound, see: [PubMed: 12489956]

(3). (a) De Favoli, P.; Prati, F. Seminars in Organic Synthesis,. 31st. Corbella, A., editor. Summer School; Brescia, Italy: Jun 19-23. 2006 p. 169-192.For recent reviews, see:(b) Arisawa M, Nishida A, Nakagawa M. JOMC. 2006; 691:5109-5121.(c) Gradillas A, Perez-Castells J. Angew. 
Chem., Int. Ed. 2006; 45:6086-6101.(d) Michaut A, Rodriguez J. Angew. Chem., Int. Ed. 2006; 45:5740-5750.

(4). Grubbs RH, Tumas W. Science. 1989; 243:907-915. [PubMed: 2645643]

(5). (a) El Sayed K, Kelly M, Kara U, Ang K, Katsuyama I, Dunbar D, Khan A, Hamann M. J. Am. Chem. Soc. 2001; 123:1804-1808. [PubMed: 11456797] (b) Yousaf M, Hammond N, Peng J, Wahyuono S, McIntosh K, Charman W, Mayer A, Hamann M. J. Med. Chem. 2004; 47:35123517. [PubMed: 15214779] (c) Sakai R, Higa T, Jefford C, Bernardinelli G. J. Am. Chem. Soc. 1986; 108:6404-6405.

(6). Winkler J, Londregan A, Hamann M. Org. Lett. 2006; 8:2591-2594. [PubMed: 16737321] Winkler J, Londregan A, Ragains J, Hamann M. Org. Lett. 2006; 8:3407-3409. [PubMed: 16836417]

(7). Ovaa H, Stapper C, van der Marel G, Overkleeft H, van Boom J, Blechert S. Tetrahedron. 2002; 58:7503-7518. 


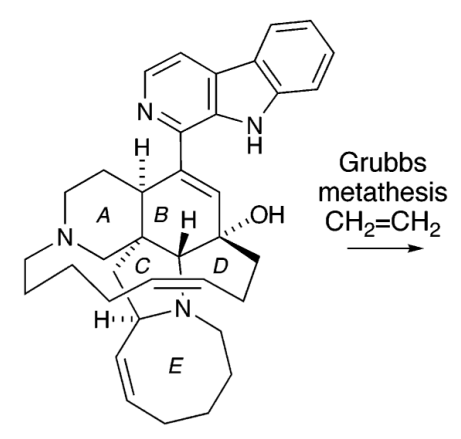

1
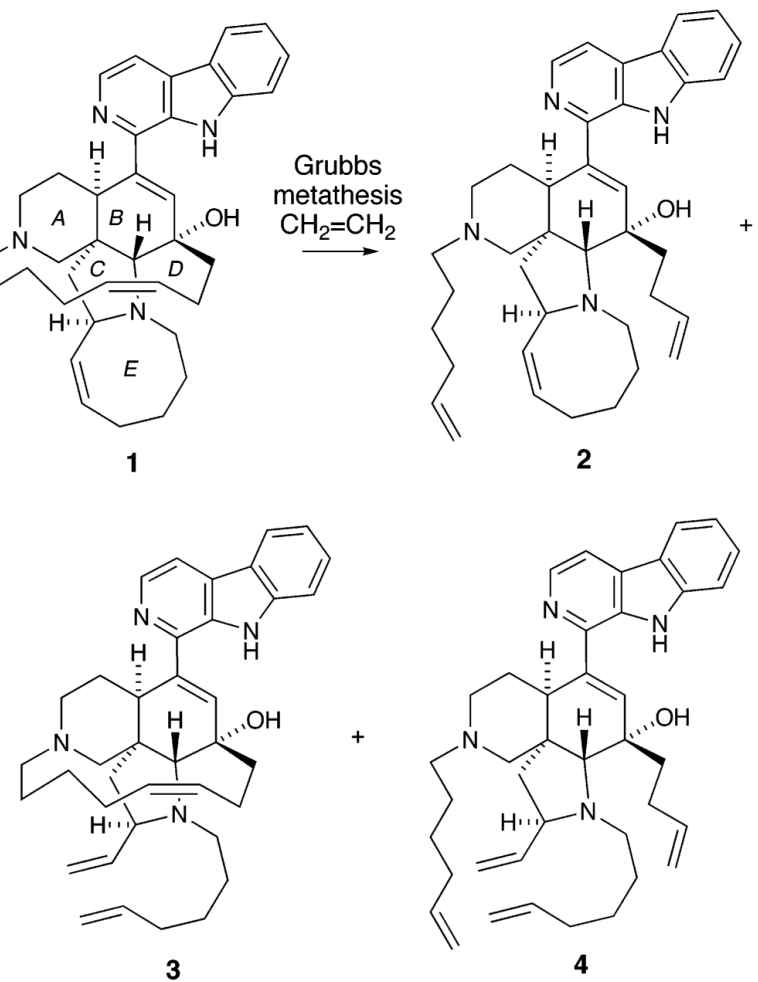

Scheme 1.

Metathetic Ring Opening of Manzamine A 1 

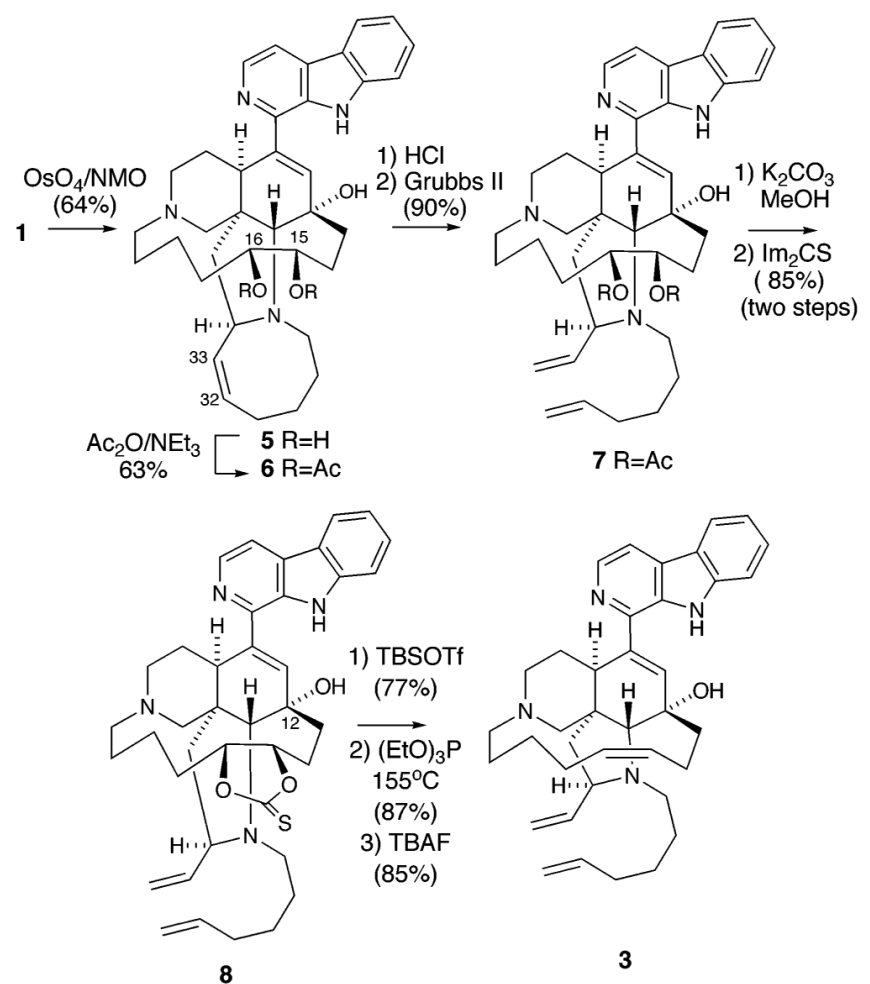

Scheme 2.

Synthesis of Tricyclic Manzamine Analogue 3

Org Lett. Author manuscript; available in PMC 2016 June 23. 
Table 1

In Vitro Screening Results of Manzamine A and Analogues

\begin{tabular}{lccc}
\hline & $\begin{array}{c}\text { P. falciparum } \\
\left.\text { (antimalarial, } \mathbf{I C}_{\mathbf{5 0}} \mathbf{n M}\right)\end{array}$ & $\begin{array}{c}\text { M. intracellulare } \\
\text { (antibacterial, } \mathbf{I C}_{\mathbf{5 0}} \mathbf{n M )}\end{array}$ & $\begin{array}{c}\text { L. donovani } \\
\text { (antiprotozoal, } \mathbf{I C}_{\mathbf{5 0}} \mathbf{n M} \text { ) }\end{array}$ \\
\hline manzamine A 1 & 25 & 0.36 & 6.2 \\
ABCE tetracyclic analogue $\mathbf{2}$ & 190 & 0.10 & 2.1 \\
ABCD tetracyclic analogue $\mathbf{3}$ & 130 & 0.43 & 29 \\
ABC tricyclic analogue 4 & 1290 & 1.6 & 7.6 \\
ciprofloxacin & & 0.18 & 47 \\
pentamidine & & & \\
chloroquine & 53 & & \\
\hline
\end{tabular}

Org Lett. Author manuscript; available in PMC 2016 June 23. 